\title{
A Novel LC-MS/MS Method Development and Validation for Ultra-trace Level Determination of Three Genotoxic Efavirenz Impurities
}

\author{
ANNAPOORNA VADLAMANI* AND K. RAVINDHRANATH \\ Department of Chemistry, Koneru Lakshmaiah Education Foundation, Green Fields, Vaddeswaram-522 502, India
}

Vadlamani and Ravindhranath: LC-MS/MS Method for Efavirenz and impurities there in

\begin{abstract}
A novel, simple, sensitive, specific and rapid reverse-phase liquid chromatography-electrospray ionizationmass spectrometry method was established and validated for the ultra-trace analysis of efavirenz-related compound $\mathrm{C}, 8$-hydroxy efavirenz and its impurity 1 , which are potential genotoxic impurities associated with efavirenz. These were separated on high performance liquid chromatography and detected with tandem mass spectrometry in the positive ionization mode with MRM transitions, $\mathbf{m} / \mathbf{z} 314.15>244.10$, 212.10 $>57.10,305.70>69.05$ and $364.15>291.25$. A gradient method was developed to separate the impurities using $0.01 \mathrm{M}$ ammonium acetate buffer and methanol at $1 \mathrm{ml} / \mathrm{min}$ flow-rate. Samples were analysed using a Hypersil $\mathrm{C}-18$ column $(5 \mu \mathrm{m}, 250 \times 4.6 \mathrm{~mm})$. The calibration curves have shown good linearity in the concentration range of $2.5-78 \mathrm{ppb}$ and a correlation coefficient of 0.99 . Mean intra and inter day precision was $2.6-3.2 \mathrm{ppm}$ and $2.5-2.6 \mathrm{ppm}$, respectively. For the 3 genotoxic impurities the limit of detection and limit of quantitation were $0.04 \mathrm{ppm}$ and $0.125 \mathrm{ppm}$, respectively. The liquid chromatographymass spectrometry/mass spectrometry method developed was specific, sensitive, precise and accurate. The developed method could be used for quantification and monitoring of genotoxic impurities of efavirenz.
\end{abstract}

Key words: Efavirenz-related genotoxic impurities, liquid chromatography-mass spectrometry/mass spectrometry method, trace-level, validation

Efavirenz (EFV, (S)-6-chloro-(cyclopropylethynyl)1,4-dihydro-4(trifluoromethyl)-2H-3,1-benzoxazin2-one) is an effective antihuman immunodeficiency virus type 1 agent that acts as a non-nucleoside reverse transcriptase inhibitor (NNRTI). Normally, NNRTI combination is the best suited for treating naive HIV patients. Some well-known NNRTI combinations are, combinations of EFV with antiretroviral (ARV) drugs like tenofovir, lamivudine, zidovudine and emtricitabine ${ }^{[1]}$. Furthermore, the mechanism of action of ARV drugs is by diffusion and circulation into the genital tract ${ }^{[2-4]}$.

Pharmacopeia of Brazil, USA, British and Japan, indicated restrictions for active pharmaceutical ingredients (APIs) and formulations for allowable levels of impurities. Moreover, the Food and Drug Administration (FDA) and International Council for Harmonisation (ICH) mentioned strategies for the identification and quantification of impurities along with residual solvent in any in novel dosage

*Address for correspondence

E-mail: annuvadlamani@gmail.com

May-June 2020 forms ${ }^{[5-9]}$. Moreover, some impurities in trace levels could affect the efficacy and safety of API, as well as be carcinogenic ${ }^{[10,11]}$. Hence, monitoring and control of trace impurities in any API turn into a very tough assignment. Therefore, the process of minimizing such carcinogenic substances became important in pharmaceutical toxicology ${ }^{[12]}$.

Based on the above documented facts, researchers mainly focused on minimizing the production of impurities in any API manufacturing process ${ }^{[13]}$. However total elimination of impurities in any process is difficult. So, the method development for accurate identification of impurities is the only option for pharmaceutical industries. Furthermore, USFDA and

\footnotetext{
This is an open access article distributed under the terms of the Creative Commons Attribution-NonCommercial-ShareAlike 3.0 License, which allows others to remix, tweak, and build upon the work non-commercially, as long as the author is credited and the new creations are licensed under the identical terms
} Indian J Pharm Sci 2020;82(3):429-434 
agency of European medicines proposed toxicological threshold limits to be $1.0-1.5 \mu \mathrm{g} / \mathrm{d}^{[14,15]}$ for genotoxic impurities.

To date, several analytical methods are defined for the quantification of EFV in biological fluids, highperformance liquid chromatography-ultraviolet/ visible (HPLC-UV/Vis) detection ${ }^{[16-20]}$, HPLC ${ }^{[21]}$, liquid chromatography-mass spectrometry $(\mathrm{LC}-\mathrm{MS})^{[22]}$, LC-MS/MS ${ }^{[23,24]}$ and ultra-performance liquid chromatography-mass spectrometry/mass spectrometry (UPLC-MS/MS) methods ${ }^{[25,26]}$. In the present work, we aimed to determine genotoxic impurities in EFV, EFV-related compound C (CPP), 8-hydroxy EFV (CPE), and EFV impurity 1 (EFI, fig. 1) using LC-MS/MS method for quantification of these impurities in EFV formulations.

\section{MATERIALS AND METHODS}

HPLC grades of ammonium acetate and methanol were purchased from Merck (Mumbai, India). CPE, EFV, $\mathrm{CPP}$ and EFI were obtained from Perfomics Analytical Labs (Hyderabad, India). A Shimadzu LC-MS/MS8050 system associated with the Nexera X2 HPLC and Lab Solutions software v.5.6 was used. Separations were accomplished on a $5 \mu \mathrm{m}$ particle size of Hypersil C18 column $(4.6 \times 250 \mathrm{~mm})$ purchased from Thermo Fisher Scientific.

\section{Method development:}

Generally, for any analysis, sample preparation plays an important role; it affects the sensitivity, as well as better recovery of impurities. So, preferable combinations of acetonitrile, water, ammonium acetate, and methanol were used as diluents for chromatographic efficiency. In the present work, $0.01 \mathrm{M}$ ammonium acetate in methanol was chosen as a diluent with column oven at $40^{\circ}$ due to good response and recovery for impurities $\mathrm{CPE}, \mathrm{CPP}$, and EFI. Also, both isocratic and gradient modes of elution were performed.

Nevertheless, from the observations, it was noticed that all the impurities were effectively separated by the gradient method. Similarly, a column of dimensions, namely Zorbax C8, Hypersil C18 column Phenomenox, Kromasil C8 and C18, were also investigated for resolutions. Finally, Hypersil C18 column was selected due to its better response, peak shape, linearity, and reproducibility even at a lower concentration. Moreover, the positive mode of ESI resulted in improved signal intensities and lesser noise background for impurities, when compared to negative mode.

\section{Method optimization:}

Mobile phase A used was prepared by dissolving $0.77 \mathrm{~g}$ of ammonium acetate in $1000 \mathrm{ml}$ Milli-Q water by sonication followed by filtration $(0.22 \mu \mathrm{m})$. Pure HPLC grade methanol was used as a mobile phase B. An LC-MS/MS system, coupled with an 8050 triple quadrupole detector, was used. Separation was achieved on a $5 \mu \mathrm{m}$ Hypersil C18 column $(250 \times 4.6 \mathrm{~mm})$ with injection volume $10 \mu 1,1 \mathrm{ml} / \mathrm{min}$ flow rate, sample cooler temperature at $15^{\circ}$ and column oven temperature $40^{\circ}$. Table 1 summarized conditions of MRM, Valco
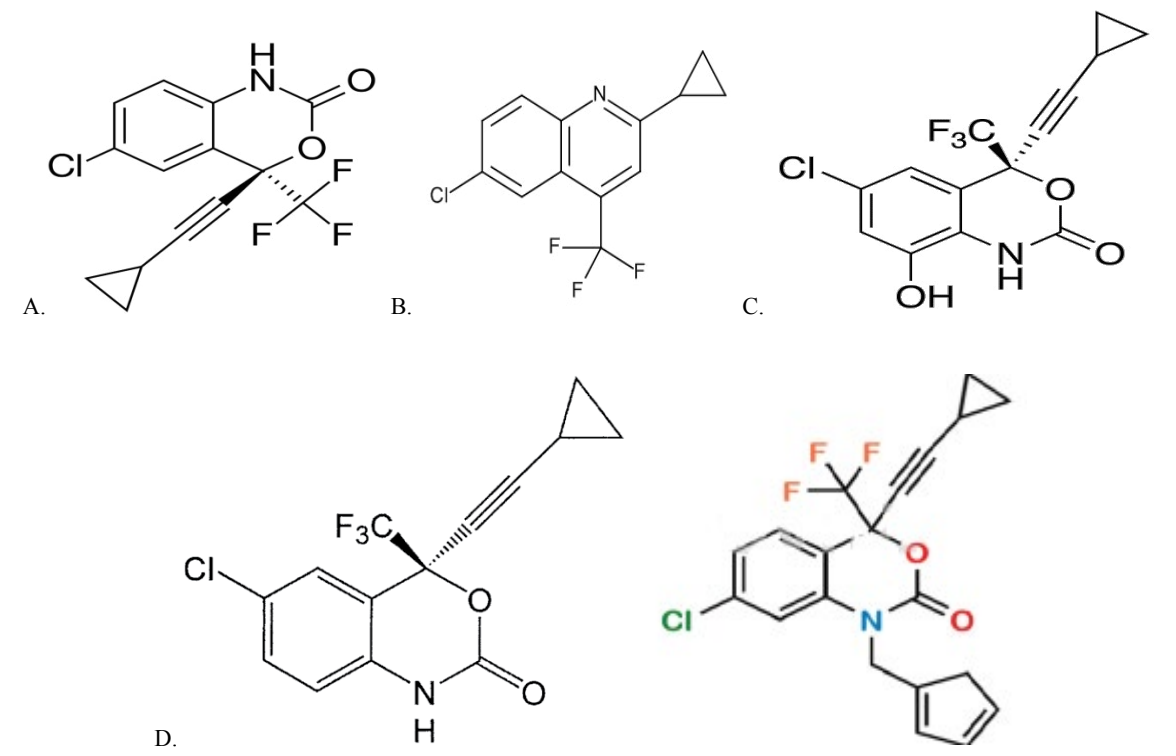

Fig. 1: Chemical structures of analytes

Chemical structures of A. efavirenz (EFV), B. efavirenz-related compound C (CPP), C. 8-hydroxy efavirenz (CPE), D. Efavirenz impurity 1 (EFI) 


\begin{tabular}{|c|c|c|c|c|c|}
\hline \multicolumn{6}{|c|}{ Gradient program } \\
\hline Time (min) & \multicolumn{3}{|c|}{ Mobile phase $\mathrm{A}$} & \multicolumn{2}{|r|}{ Mobile phase $B$} \\
\hline 0.01 & \multicolumn{3}{|c|}{45} & \multicolumn{2}{|r|}{55} \\
\hline 8.00 & \multicolumn{3}{|c|}{45} & \multicolumn{2}{|r|}{55} \\
\hline 10.00 & \multicolumn{3}{|c|}{20} & \multicolumn{2}{|r|}{80} \\
\hline 13.50 & \multicolumn{3}{|c|}{ Total Flow } & \multicolumn{2}{|r|}{$0.8 \mathrm{ml}$} \\
\hline 15.00 & \multicolumn{3}{|c|}{45} & \multicolumn{2}{|r|}{55} \\
\hline 17.00 & \multicolumn{3}{|c|}{45} & \multicolumn{2}{|r|}{55} \\
\hline 17.00 & \multicolumn{3}{|c|}{ Total Flow } & \multicolumn{2}{|r|}{$0.8 \mathrm{ml}$} \\
\hline 20.00 & \multicolumn{3}{|c|}{ Total Flow } & \multicolumn{2}{|r|}{$1 \mathrm{ml}$} \\
\hline 21.50 & \multicolumn{3}{|c|}{20} & \multicolumn{2}{|r|}{80} \\
\hline 32.00 & \multicolumn{3}{|c|}{45} & \multicolumn{2}{|r|}{55} \\
\hline 37.00 & \multicolumn{3}{|c|}{ Controller } & \multicolumn{2}{|r|}{ Stop } \\
\hline \multicolumn{6}{|c|}{ Multiple reactions monitoring conditions } \\
\hline & \multicolumn{5}{|c|}{ Parameters } \\
\hline Impurity & MRM & Q1 Prebias & CE & Q3 Prebias & Dwell time (milliseconds) \\
\hline CPP IMP & $212.10>57.10$ & -26.0 & -22.0 & -24.0 & 100 \\
\hline CPE IMP & $305.70>69.05$ & 20.0 & 22.0 & 24.0 & 100 \\
\hline $\begin{array}{l}\text { Efavirenz } \\
\text { Impurity } 1\end{array}$ & $364.15>291.25$ & 22.0 & 22.0 & 30.0 & 100 \\
\hline Efavirenz & $314.15>244.10$ & 20.0 & 19.0 & 26.0 & 100 \\
\hline \multicolumn{6}{|c|}{ Valco Valve Condition for sample method } \\
\hline & $\min )$ & \multicolumn{2}{|c|}{ Command } & \multicolumn{2}{|r|}{ Value } \\
\hline & & \multicolumn{2}{|c|}{$\mathrm{FCV} 2=$} & \multicolumn{2}{|r|}{1} \\
\hline & & \multicolumn{2}{|c|}{$\mathrm{FCV} 2=$} & \multicolumn{2}{|r|}{0} \\
\hline
\end{tabular}

valve, and source gas parameters for mobile phases A and $\mathrm{B}$ under gradient mode against the blank solution (diluent). In order to safeguard the ESI sourced from high EFV concentrations, the valve ailment is kept under enabling transferral of eluent to unwanted.

\section{Standard preparation:}

Separately, $2.6 \mathrm{mg}$ of CPE, CPP and EFI were weighed accurately and dissolved completely in $100 \mathrm{ml}$ diluent via sonication. One milliliter of the above impurity/ intermediate standard stock solution was further diluted to $100 \mathrm{ml}$ with diluent. One hundred milligrams of accurately weighed EFV was diluted to $5 \mathrm{ml}$. To evaluate the system suitability parameters, $10 \mu \mathrm{l}$ of the above-prepared solution was separately injected namely blank, standard, and sample preparations and their peak area responses were monitored. As per the pharmacopeias, the average peak area response of $\%$ relative standard deviation (RSD) of CPE, CPP, and EFI impurities should not be more than 15.0.

\section{Method validation:}

Method was validated according to the USFDA and $\mathrm{ICH}$ guidelines. The appropriateness and efficacy of the chromatographic scheme were obtained from the system suitability test and it is proficient in the investigation without any bias. To guarantee the capacity of the chromatographic systems, these must placate pre-defined acceptance conditions to implement the examination of various samples. In the contemporary experiment, CPE, CPP, EFI impurity solutions were injected into the LC-MS/MS system for determining system suitability parameters such as peak area and its RSD and retention time, which were detailed after data incorporation using software (Table 2; fig. 2).

The CPE, CPP and EFI impurities were also checked for specificity by injecting them against the blank solution. The outcomes showed that the chosen method is unbiased concerning the presence of further components and interestingly, no nosiness was recorded at the RTs of CPE, CPP, and EFI impurities (Table 3 and fig. 3).

\section{RESULTS AND DISCUSSION}

At limit of quantification (LOQ), 4 levels of the precision method, namely system precision, intermediate precision (ruggedness), method precision (repeatability) and precision were evaluated. System precision suggested inconsistency in the dimensions of the analytical system, while repeatability (method precision) indicated the reproducibility of the method. Standard solution was prepared with CPE, CPP, and 
TABLE 2: RESULTS FOR SYSTEM SUITABILITY

\begin{tabular}{llll}
\hline System suitability parameters & CPP & CPE & EFI \\
\hline $\begin{array}{l}\text { \% RSD of Peak areas obtained from six } \\
\begin{array}{l}\text { replicate injections of the standard } \\
\text { solution }\end{array}\end{array}$ & 0.8 & 1.2 & 1.6 \\
\hline
\end{tabular}

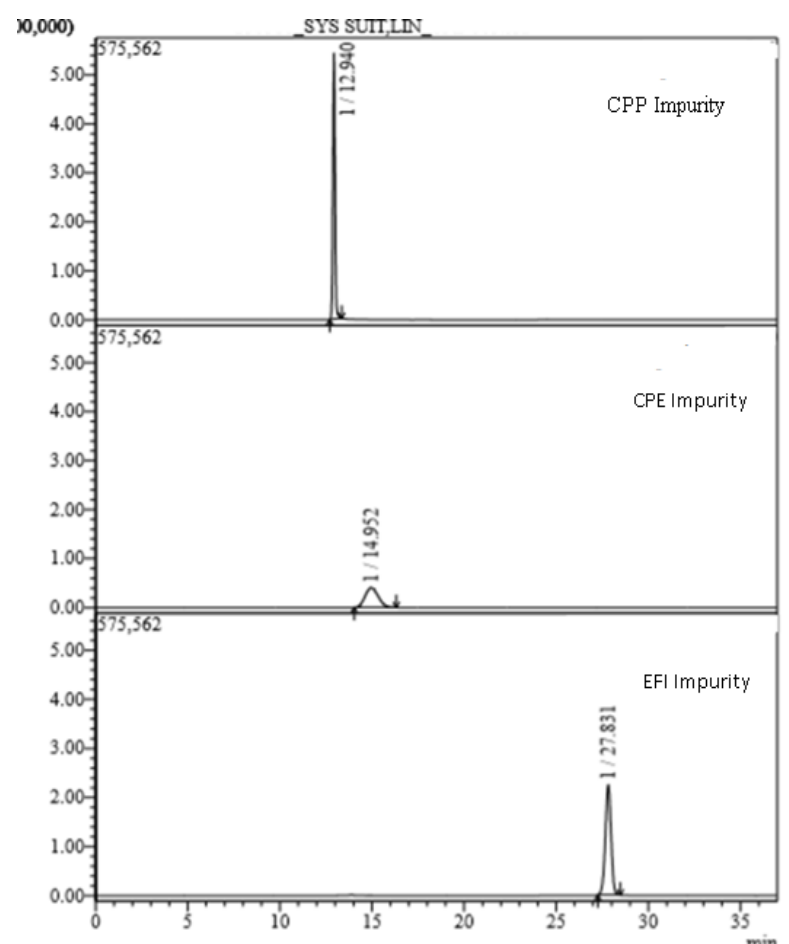

Fig. 2: System suitability

\section{TABLE 3: BLANK INTERFERENCE RESULTS FOR CPP, CPE, AND EFI}

\begin{tabular}{lcc}
\hline Name & $\begin{array}{c}\text { Retention } \\
\text { time }(\text { min) }\end{array}$ & $\begin{array}{r}\text { Interference found at the retention } \\
\text { time of CPP, CPE, and EFI }\end{array}$ \\
\hline CPP & 12.940 & No \\
CPE & 14.952 & No \\
EFI & 27.831 & No \\
Blank & NA & No \\
\hline
\end{tabular}

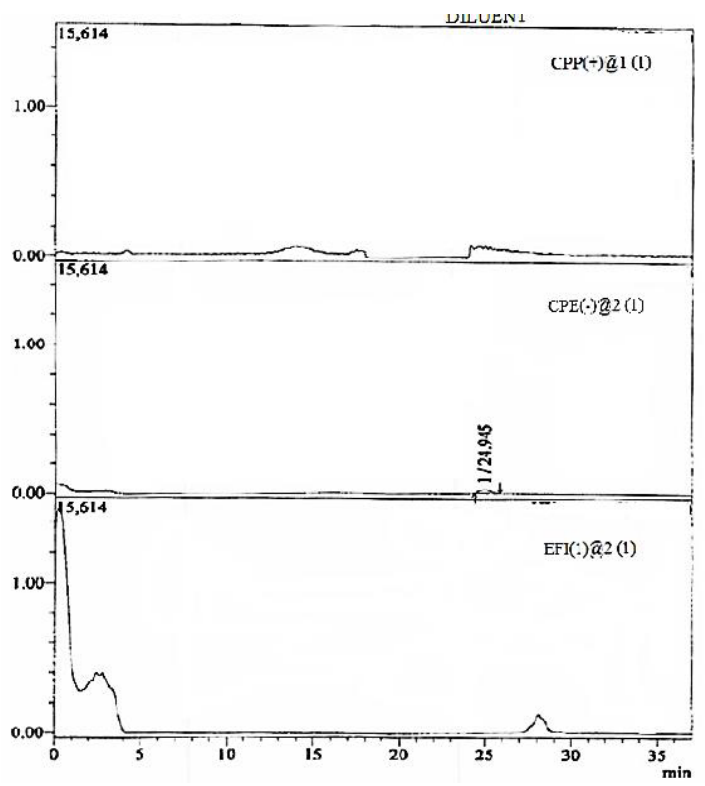

Fig. 3: Specificity
EFI impurities and injected $(n=6)$ into the LC-MS/MS system from which peak area and RSD were derived, whereas form method precision, the \% RSD data was obtained (Table 4). The results of \% RSD of CPE, CPP and EFI impurities were set up to be within the acceptance limits (Table 5).

Furthermore, to create an in lines connection amongst the concentration/quantity of analyte existing in the sample taken and to the detector response, a set of standards of calibration were equipped. Moreover, linearity was calculated by formulating 5 to $150 \%$ of standard concentrations.

The peak area of each sample was noted and plotted against respective concentrations. The Eqn.

TABLE 4: METHOD PRECISION RESULTS FOR CPP, CPE AND EFI

\begin{tabular}{lccc}
\hline Preparation & CPP $(\mathbf{p p m})$ & CPE $(\mathbf{p p m})$ & EFI $(\mathrm{ppm})$ \\
\hline 1 & 2.5 & 2.8 & 3.0 \\
2 & 2.6 & 2.9 & 3.1 \\
3 & 2.7 & 3.0 & 3.2 \\
4 & 2.7 & 2.9 & 3.2 \\
5 & 2.8 & 3.1 & 3.4 \\
6 & 2.5 & 2.7 & 3.1 \\
Average & 2.6 & 2.9 & 3.2 \\
\% RSD & 4.6 & 4.9 & 4.3 \\
\hline
\end{tabular}

TABLE 5: INTERMEDIATE PRECISION RESULTS FOR CPP, CPE, AND EFI

\begin{tabular}{lccc}
\hline Preparation & CPP (ppm) & CPE (ppm) & EFI (ppm) \\
\hline 1 & 2.5 & 2.6 & 2.5 \\
2 & 2.5 & 2.6 & 2.5 \\
3 & 2.6 & 2.6 & 2.5 \\
4 & 2.5 & 2.6 & 2.5 \\
5 & 2.5 & 2.6 & 2.5 \\
6 & 2.6 & 2.7 & 2.6 \\
Average & 2.5 & 2.6 & 2.5 \\
\% RSD & 2.0 & 1.6 & 1.6
\end{tabular}

$\%$ RSD for twelve determinations (precision \& intermediate precision)

\begin{tabular}{lccc}
\hline Preparation & CPP $(\mathbf{p p m})$ & CPE $(\mathrm{ppm})$ & EFI (ppm) \\
\hline 1 & 2.5 & 2.8 & 3.0 \\
2 & 2.6 & 2.9 & 3.1 \\
3 & 2.7 & 3.0 & 3.2 \\
4 & 2.7 & 2.9 & 3.2 \\
5 & 2.8 & 3.1 & 3.4 \\
6 & 2.5 & 2.7 & 3.1 \\
7 & 2.5 & 2.6 & 2.5 \\
8 & 2.5 & 2.6 & 2.5 \\
9 & 2.6 & 2.6 & 2.5 \\
10 & 2.5 & 2.6 & 2.5 \\
11 & 2.5 & 2.6 & 2.5 \\
12 & 2.6 & 2.7 & 2.6 \\
Average & 2.6 & 2.8 & 2.8 \\
$\%$ RSD & 4.0 & 6.5 & 12.4 \\
\hline
\end{tabular}


www.ijpsonline.com

TABLE 6: LINEARITY OF CPP, CPE, AND EFI

\begin{tabular}{|c|c|c|c|c|c|c|}
\hline \multicolumn{7}{|c|}{ Linearity results } \\
\hline \multirow{2}{*}{ Levels } & \multicolumn{2}{|c|}{ CPP IMP } & \multicolumn{2}{|c|}{ CPE IMP } & \multicolumn{2}{|c|}{ EFI IMP } \\
\hline & Conc. in $\mathrm{ppb}$ & Area & Conc. in ppb & Area & Conc. in $\mathrm{ppb}$ & Area \\
\hline $5 \%$ & 2.508 & 259187 & 2.531 & 117538 & 2.569 & 305901 \\
\hline $10 \%$ & 5.224 & 298024 & 5.272 & 137684 & 5.352 & 388002 \\
\hline $25 \%$ & 12.538 & 1214979 & 12.653 & 619137 & 12.845 & 1482624 \\
\hline $50 \%$ & 25.075 & 2661829 & 25.306 & 1341802 & 25.690 & 3110678 \\
\hline $75 \%$ & 37.613 & 3873591 & 37.958 & 1991286 & 38.534 & 4712314 \\
\hline $100 \%$ & 50.046 & 4817911 & 50.506 & 2451722 & 51.272 & 5857968 \\
\hline $125 \%$ & 62.688 & 6522284 & 63.264 & 3349419 & 64.224 & 8271495 \\
\hline $150 \%$ & 75.748 & 8502919 & 76.444 & 4296518 & 77.604 & 11062322 \\
\hline Slope & \multicolumn{2}{|c|}{107848} & \multicolumn{2}{|c|}{55129} & \multicolumn{2}{|c|}{129684} \\
\hline Intercept & \multicolumn{2}{|c|}{-165458.4} & \multicolumn{2}{|c|}{-87086.3} & \multicolumn{2}{|c|}{-234051.5} \\
\hline Correlation & \multicolumn{2}{|c|}{0.9974} & \multicolumn{2}{|c|}{0.9994} & \multicolumn{2}{|c|}{0.9976} \\
\hline
\end{tabular}

TABLE 7: LOD AND LOQ ESTABLISHMENT RESULTS

\begin{tabular}{lcc}
\hline Impurity & Limit of detection & Limit of quantification \\
\cline { 2 - 3 } name & in ppm & in ppm \\
\hline CPP & 0.04 & 0.125 \\
CPE & 0.04 & 0.125 \\
EFI & 0.04 & 0.125 \\
\hline
\end{tabular}

TABLE 8: LOQ PRECISION RESULTS

\begin{tabular}{lccc}
\hline LOQ Preparation & CPP $(\mathrm{ppb})$ & $\mathrm{CPE}(\mathrm{ppb})$ & $\mathrm{EFI}(\mathrm{ppb})$ \\
\hline Preparation-1 & 1597 & 1268 & 1396 \\
Preparation-2 & 1601 & 1301 & 1403 \\
Preparation-3 & 1583 & 1342 & 1405 \\
Preparation-4 & 1576 & 1296 & 1413 \\
Preparation-5 & 1605 & 1304 & 1426 \\
Preparation-6 & 1597 & 1344 & 1419 \\
Average & 1593.2 & 1309.2 & 1410.3 \\
\%RSD & 0.7 & 2.2 & 0.8 \\
\hline
\end{tabular}

TABLE 9: LOQ ACCURACY RESULTS

\begin{tabular}{lccc}
\hline LOQ preparation & CPP $(\mathrm{ppm})$ & CPE $(\mathrm{ppm})$ & $\mathrm{EFI}(\mathrm{ppm})$ \\
\hline Preparation-1 & 110.6 & 116.2 & 115.3 \\
Preparation-2 & 114.1 & 117.1 & 112.6 \\
Preparation-3 & 115.7 & 117.5 & 111.5 \\
Preparation-4 & 112.9 & 115.1 & 111.6 \\
Preparation-5 & 116.7 & 121.6 & 115.8 \\
Preparation-6 & 113.7 & 116.4 & 115.0 \\
\hline
\end{tabular}

$y=m x+b$, defined the linear relation between impurity concentration (x) and respective peak area (y). From this analysis, a correlation coefficient (must be above 0.99 ) and slope-intercept values were derived (Table 6). Hence, the coefficient for CPE, CPP and EFI impurity peak was found to be 0.99 each, which indicated good linearity (Table 6). Similarly, a signal-to-noise ratio for impurities of limit of detection (LOD) and LOQ were predictable at 3:1 and 10:1, respectively (Table 7). Also, Table 8 and 9 shows the \% RSD values of impurities $(n=6)$, and the RSD of peak areas, respectively. The
$\mathrm{S} / \mathrm{N}$ ratio for performing precision of LOQ and LOQ solutions $(n=6)$ was found to be 10:1.

A novel LC-MS/MS method was established and validated for the ultra-trace-level identification of three PGI, namely CPE, CPP, and EFI in EFV. For this analysis, a switching valve was used not only to guard the ESI source but also to afford favorable analysis conditions. Furthermore, the MRM-mode method afforded good sensitivity and the LOD and LOQ values were measured to be minimal for all the 3 impurities. Based on the data of analysis, it could be justified that this method is validated completely with acceptable parameters like accuracy, linearity, and precision. Moreover, this method was also found to be simple and sensitive. Hence, this analytical method could be used as a tool for quality control, as well as checking of PGI in EFV.

\section{Acknowledgments:}

The authors would like to thank the following for providing necessary facilities to carry out this research work. Koneru Lakshmaiah Education Foundation, Green Fields, Vaddeswaram-522 502, Guntur, Andhra Pradesh, India, and Perfomics Analytical Labs LLP, Nacharam, Hyderabad, Telangana 500076, India.

\section{Conflict of interest:}

The authors report no conflict of interest in this work.

\section{REFERENCES}

1. Hoffman JT, Rossi SS, Espina-Quinto R, Letendre S, Capparelli EV. Determination of efavirenz in human dried blood spots by reversed-phase high-performance liquid chromatography with UV detection. Ther Drug Monit 2013;35:150-62.

2. Cao YJ, Hendrix CW. Male genital tract pharmacology: Quantitative methods to better understand a complex peripheral compartment. Clin Pharmacol Ther 2008;83:401-12. 
3. Singh SK, Singh SK. Human immunodeficiency virus (HIV) infection. In: Diagnostics to pathogenomics of sexually transmitted infections. Science, John Wiley Sons 2018;19:6181.

4. Paidi KR, Tatipamula VB, Kolli MK, Pedakotla VR. Benzohydrazide incorporated imidazo [1, 2-b] pyridazine: Synthesis, characterization and in vitro anti-tubercular activity. Int J Chem Sci 2017;15:172.

5. ICH, Q3A, (R1): Impurities in New Drug Substances (Revised Guideline), Geneva; 2002.

6. ICH, Q3B, (R1): Impurities in New Drug Products (Revised Guideline), Geneva; 2003.

7. Narayana MB, Chandrasekhar KB, Rao BM. Quantification of genotoxic impurity 2-butyl p-toluene- sulfonate at ppm level by LCMS/MS in the naproxen drug substance. J Chromatogr Sci 2014;52:818-25.

8. Kolli MK, Padi KR, Singh N, Tatipamula VB, Reddy RP. Synthesis and in vitro antimycobacterialactivity of some novel pyrrolo[1,2-A]pyrazine incorporated indolizine derivatives. Der Pharma Chem 2018;10:153-8.

9. Tatipamula VB, Talluri MR, Ketha A, Battu GR, Swamy R. Protective effect of Aurelia aurita against free radicals and strepto-zotocin-induced diabetes. Bangladesh J Pharmacol 2018;13:287-95.

10. Tatipamula VB, Kolli MK, Lagu SB, Paidi KR, Reddy $\mathrm{R}$, Yejella RP. Novel indolizine derivatives lowers blood glucose levels in Streptozotocin-induced diabetic rats: A histopathological approach. Pharmacol Rep 2019;71:23342.

11. Haritha P, Patnaik SK, Tatipamula VB. Chemical and pharmacological evaluation of manglicolous lichen Graphis ajarekariI Patw. \& CR Kulk. Vietnam J Sci Technol 2019;57:300-8.

12. Bhujanga Rao C, Babu DC, Bharadwaj TV, Srikanth D, Vardhan KS, Raju TV, et al. Isolation, structural assignment and synthesis of (SE)-2-methyloctyl 3-(4-methoxyphenyl) propenoate from the marine soft coral Sarcophyton ehrenbergi. Nat Prod Res 2015;29:70-6.

13. International Conference on Harmonization Quality Guidelines III/5442/94-EN, Impurities in New Drug Substances, Federal Register 1996; 61:372-4.

14. EMEA-CHMP, Guidelines on the limit of Genotoxic Impurities. CPMP/SWP/5199/02, EMEA-CHMP/QMP/251344/2006, 28 June; 2006.

15. USFDA, Guidelines for industry: Genotoxic and carcinogenic impurities in drug substances and products, recommended approaches 2008 .

16. Tatipamula VB, Vedula GS. In vitro anti-inflammatory and cytotoxicity studies of two mangrove associated lichens,
Dirinaria consimilis and Ramalina leiodea extracts. Hygeia JD Med 2018;10(1):16-26.

17. Tatipamula VB, Vedula GS, Sastry AV. Antarvediside AB from manglicolous lichen Dirinaria consimilis (Stirton) DD Awasthi and their pharmacological profile. Asian J Chem 2019;31:80512.

18. Weller DR, Brundage RC, Balfour Jr HH, Vezina HE. An isocratic liquid chromatography method for determining HIV non-nucleoside reverse transcriptase inhibitor and protease inhibitor concentrations in human plasma. J Chromatogr B Analyt Technol Biomed Life Sci 2007;848:369-373.

19. Paidi KR, Tatipamula VB, Kolli MK, Annam SS, Pedakotla VR. Synthesis of imidazo [1, 2-b] pyridazine comprised piperazine, morpholine derivatives as potent antimycobacterial agents with in vivo locomotor activity. Anti-Infective Agents 2017;15:131-9.

20. Tatipamula VB, Killari KN, Gopaiah KV, Ketha A. GCMS Analysis of Ethanol Extract of Taxithelium napalense (Schwaerg) Broth along with its alpha-Glucosidase Inhibitory Activity. Indian J Pharm Sci 2019;81(3):569-74.

21. Kwara A, Lartey M, Sagoe KW, Xexemeku F, Kenu E, Oliver-Commey $\mathrm{J}$, et al. Pharmacokinetics of efavirenz when co-administered with rifampin in TB/ HIV co-infected patients: Pharmacogenetic effect of CYP2B6 variation. J Clin Pharmacol 2008;48:1032-40.

22. Tatipamula VB, Kukavica B. Protective effects of extracts of lichen Dirinaria consimilis (Stirton) DD Awasthi in bifenthrinand diazinon-induced oxidative stress in rat erythrocytes in vitro. Drug Chem Toxicol 2020:1-8.

23. Avery LB, Parsons TL, Meyers DJ, Hubbard WC. A highly sensitive ultraperformance liquid chromatography-tandem mass spectrometric (UPLC-MS/MS) technique for quantitation of protein free and bound Efavirenz (EFV) in human seminal and blood plasma. J Chromatogr B 2010;878:3217-24.

24. Tatipamula VB, Vedula GS, Sastry AV. Chemical and pharmacological evaluation of manglicolous lichen Roccella montagnei Bel em. DD Awasthi. J Pharm Sci 2019;5:8.

25. Venkatesham K, Babu DC, Bharadwaj TV, Bunce RA, Rao $\mathrm{CB}$, Venkateswarlu Y. Synthesis of n-alkyl terminal halohydrin esters from acid halides and cyclic ethers or thioethers under solvent-and catalyst-free conditions. RSC Advances 2014;4:51991-4.

26. Notari S, Mancone C, Alonzi T, Tripodi M, Narciso P, Ascenzi $\mathrm{P}$, et al. Determination of abacavir, amprenavir, didanosine, efavirenz, nevirapine, and stavudine concentration in human plasma by MALDI-TOF/TOF. J Chromatogr B Analyt Technol Biomed Life Sci 2008;863:249-57. 